\title{
Hygrothermal simulation assessment of internal insulation systems for retrofitting a historic Danish building
}

\author{
Vasilis Soulios ${ }^{1, *}$, Ernst Jan de Place Hansen ${ }^{1}$, and Ruut Peuhkuri ${ }^{1}$ \\ ${ }^{1}$ Danish Building Research Institute, Aalborg University Copenhagen, Denmark
}

\begin{abstract}
The built environment is accountable for $1 / 3$ of the European energy consumption. Thermal insulation is a key factor affecting the energy performance of buildings. Historic buildings typically were made with solid external walls of brick masonry or natural stone, rarely insulated afterwards. Often the buildings have worth-preserving façades making internal insulation the only feasible technique, however significantly modifying the hygrothermal performance of the façade. The research objective of this paper is to simulate the hygrothermal performance of solid masonry walls in an old Danish hospital that will be internally insulated following the Danish requirement (U-value) for external walls (change of use of buildings) and transformed into dwellings, involving different insulation systems. Heat loss and masonry moisture content level after adding internal insulation and the possible effects of hydrophobization on the moisture content is simulated. Simulations show an increased moisture content in the original wall when adding internal insulation implying an increased risk for moisture-related damage (mould growth, frost damage and interstitial condensation). The results also show that hydrophobic impregnation of the internally insulated facades may be vital in avoiding moisture problems and securing a moisture-safe energy renovation of buildings like the one studied.
\end{abstract}

\section{Introduction}

Internal insulation is often the only renovation option in the case of historic buildings with worth-preserving façades (constructed before 1945) [1]. However, internally insulating a massive wall can lead to several moisture problems [2]. This highlights the need of moisture-safe energy renovation of historic buildings, e.g. based on hygrothermal simulations. As part of the transformation of a former hospital located in the Danish town Dianalund into dwellings, the behaviour of internal insulated walls was simulated. The renovation is targeting at upgrading the hygrothermal behaviour of the building with the addition of internal insulation and hydrophobic impregnation at the external walls.

Initially, the study contemplates the required thickness of different insulation system in order to meet the Danish requirements for renovation at change of use. Subsequently, the

\footnotetext{
* Corresponding author: vas@sbi.aau.dk
} 
study investigates heat loss and moisture content levels inside the masonry after adding internal insulation and the potential moisture-related damages that can occur, such as mould growth on the interior finishing, frost damage, and interstitial condensation in the interface between the masonry and the internal insulation. Additionally, the potential effect of hydrophobization at a south-west oriented façade is studied.

\section{Simulation input}

Hygrothermal simulations were conducted via Delphin software [3]. Table 1 and Figure 1 desribe the properties of the masonry, the insulation materials and further materials being part of the simulated insulation systems. Four types of insulation systems were included, representing a vapour tight system (XPS, mineral wool with vapour barrier), a capillary active system $(\mathrm{CaSi})$ and a partly capillary active system (iQ-Therm). Masonry properties used in the simulations was created by altering the properties of «Old building brick (Dresden $\mathrm{ZH}$ )» in the Delphin database to match the properties of a brick sample from the Dianalund building measured at the Technical University of Denmark.

Table 1. Material properties of wall elements used for hygrothermal simulation. Density $(\rho)$, specific heat capacity $\left(c_{p}\right)$, thermal conductivity $(\lambda)$, moisture content at saturated condition $\left(w_{\text {sat }}\right)$, capillary moisture content $\left(w_{\text {cap }}\right)$, capillary water uptake coefficient $\left(A_{w}\right)$ and water vapour diffusion factor $(\mu)$.

\begin{tabular}{|c|c|c|c|c|c|c|c|}
\hline & $\begin{array}{c}\boldsymbol{\rho} \\
{\left[\mathbf{k g} / \mathbf{m}^{3}\right]}\end{array}$ & $\begin{array}{c}\boldsymbol{c}_{\boldsymbol{p}} \\
{[\mathbf{J} /(\mathbf{k g} \mathbf{K})]}\end{array}$ & $\begin{array}{c}\boldsymbol{\lambda} \\
{[\mathbf{W} /(\mathbf{m} \mathbf{K})]}\end{array}$ & $\begin{array}{c}\boldsymbol{w}_{\text {sat }} \\
{\left[\mathbf{m}^{\mathbf{3}} / \mathbf{m}^{\mathbf{3}}\right]}\end{array}$ & $\begin{array}{c}\boldsymbol{w}_{\text {cap }} \\
{\left[\mathbf{m}^{\mathbf{3}} / \mathbf{m}^{\mathbf{3}}\right]}\end{array}$ & $\begin{array}{c}\boldsymbol{A}_{\boldsymbol{w}} \\
{\left[\mathbf{k g} /\left(\mathbf{m}^{\mathbf{2}} \sqrt{\mathbf{s}}\right)\right]}\end{array}$ & $\begin{array}{c}\boldsymbol{\mu} \\
{[-]}\end{array}$ \\
\hline Masonry & 1857 & 797 & 0.546 & 0.303 & 0.288 & 0.306 & 12 \\
\hline Lime plaster & 1800 & 850 & 0.820 & 0.285 & 0.253 & 0.127 & 12 \\
\hline XPS & 35 & 1500 & 0.027 & 0.905 & & $8 \mathrm{E}-06$ & 225 \\
\hline CaSi & 351 & 902 & 0.067 & 0.850 & 0.807 & 1.330 & 9.2 \\
\hline iQ-Therm & 49 & 1400 & 0.037 & 0.090 & 0.070 & 0.013 & 27 \\
\hline Mineral wool & 134 & 840 & 0.040 & 0.900 & 0.900 & 0.000 & 1 \\
\hline Gypsum board & 850 & 850 & 0.200 & 0.551 & 0.400 & 0.277 & 10 \\
\hline iQ fix & 1313 & 863 & 0.496 & 0.277 & 0.200 & 0.005 & 18.7 \\
\hline iQ top & 1269 & 1453 & 0.478 & 0.327 & 0.210 & 0.222 & 13.9 \\
\hline
\end{tabular}

A target U-value of $0.15 \mathrm{~W} /\left(\mathrm{m}^{2} \mathrm{~K}\right)$ was used [4] (change of use of buildings), resulting in different thickness of the insulation included in the simulation, cf. differences in thermal conductivity of the insulation materials. Each insulation system is composed of different layers and the wall composition may vary according to each insulation system (see Figure 1).

For each insulation system, the thickness used in the simulation was in accordance with the U-value requirement and available commercial boards. Therefore, for XPS simulation included a board with a thickness of $160 \mathrm{~mm}$, for CaSi eight boards of $50 \mathrm{~mm}$, for iQTherm two boards of $80 \mathrm{~mm}$ plus two boards of $30 \mathrm{~mm}$ and for mineral wool two boards of $95 \mathrm{~mm}$ plus one board of $45 \mathrm{~mm}$.

The simulations were one-dimensional and therefore, some aspects of the construction, like mortar joints and wooden beams were neglected and the masonry wall was simulated as one isotropic brick material. 


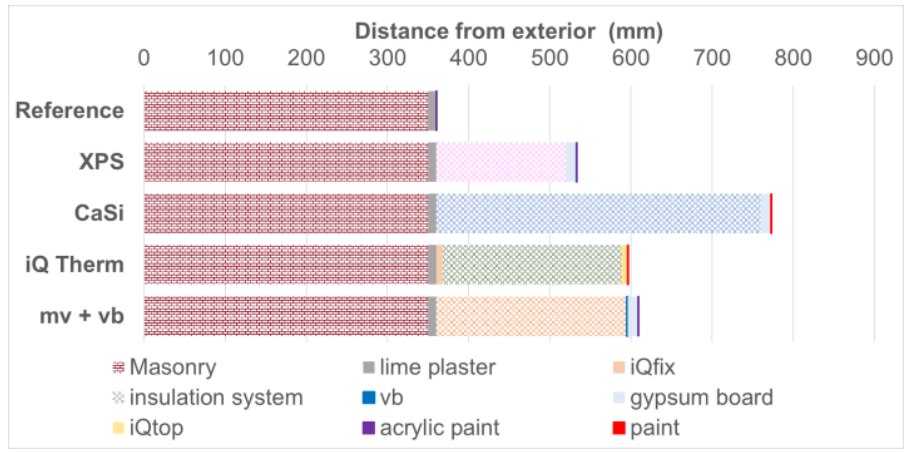

Fig. 1. Wall composition with internal insulation to reach $U=0.15 \mathrm{~W} /\left(\mathrm{m}^{2} \mathrm{~K}\right)$. Vapour barrier (vb) $s_{d}=$ $70 \mathrm{~m}$ (mineral wool (mw) system), acrylic paint $s_{d}=0.18 \mathrm{~m}$, and paint $s_{d}=0.01 \mathrm{~m}$. $s_{d}$ : equivalent air layer thickness $(\mu *$ material thickness).

Climatic data for Copenhagen were based on [5], containing estimations for future climate. The duration of the simulations was five years, starting $1^{\text {st }}$ of January $2020(12: 00 \mathrm{am})$. South-west (SW) and north-east (NE) facades were simulated as being worst-case scenarios in Denmark; SW being the most exposed orientation with regard to wind driven rain, whereas very little solar radiation reaches northbound facades. The indoor conditions were considered to be constant $\left(20{ }^{\circ} \mathrm{C}\right.$ and $\left.50 \% \mathrm{RH}\right)$.

The main goal of this preliminary study is to investigate potential moisture-related damage induced by the internal insulation systems before their implementation. The effect of hydrophobization was simulated using a simplified approach of neglecting the wind driven rain [6].

\section{Simulation results}

\subsection{Moisture content}

Figure 2 shows the moisture content in the masonry at SW-oriented facades for the $5^{\text {th }}$ year of simulation. The reference wall has the lowest moisture content but it does not dry out during the year. Adding any kind of internal insulation increases the moisture content. $\mathrm{CaSi}$ shows the lowest increase, probably because it is capillary active and part of the moisture in the masonry is transferred inwards to the insulation and eventually the indoor climate. XPS and mineral wool with vapour barrier experience the highest moisture contents probably because they are vapour tight. iQ-Therm illustrates a slightly lower moisture content than XPS and mineral wool which might be due to the capillary active channels in the boards of this system. The fact that the moisture in the masonry do not dry out in any wall configuration illustrates a potential risk for moisture-related damage.

The moisture content of the uninsulated hydrophobized masonry wall is almost zero during the year while adding an insulation system results in slightly elevated moisture content in the masonry during winter that is dried out during the year. In the hydrophobized case the presence of moisture during winter was probably induced by the simplified way of simulating hydrophobization (neglecting wind driven rain). The moisture content probably exists due to condensation at cold exterior wall surfaces that occurs from the high outdoor RH during winter in Denmark. The simulation shows that it exists only in the exterior part of the masonry, which is not expected to happen in a real hydrophobized wall.

The simulated moisture content in masonry that is not hydrophobized at NE-oriented façades was significantly lower compared to SW for all the wall configurations but also never dries out during the year. 


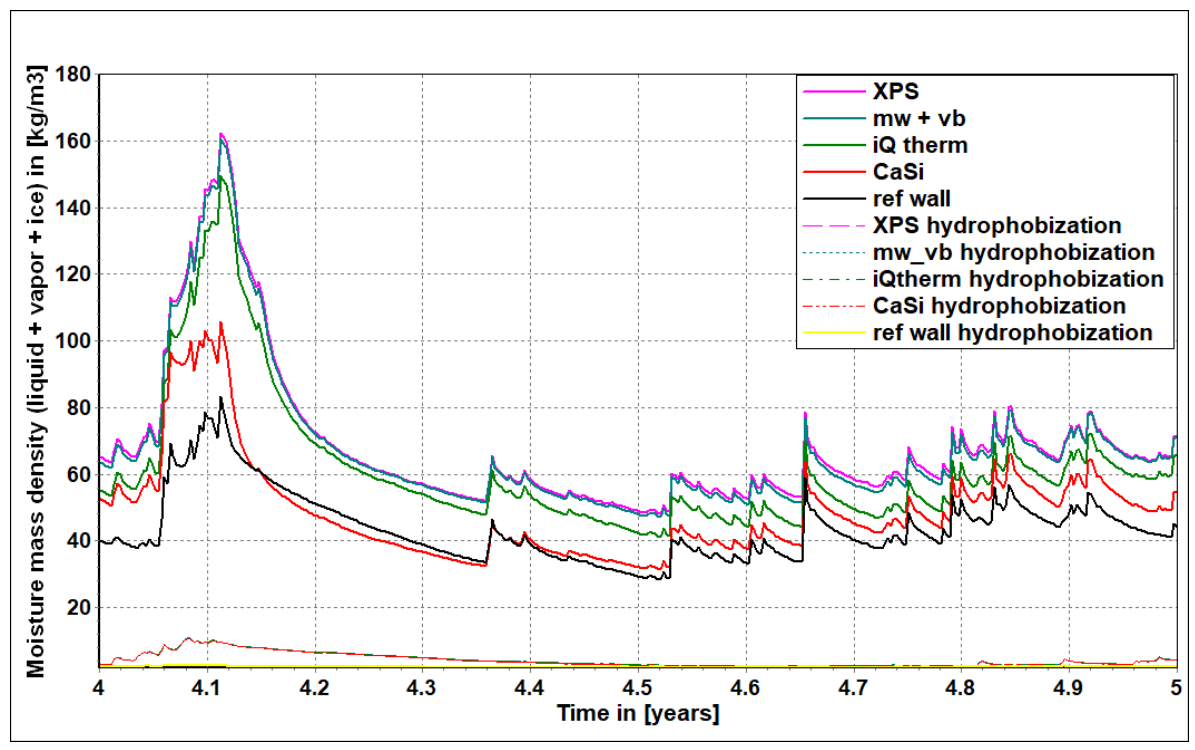

Fig. 2. Moisture content in the masonry in five different, SW-oriented wall configurations, including reference wall. Simulation with and without wind driven rain, representing a brick wall before and after hydrophobization (simplified approach). Simulation based on climate data for Copenhagen 2020-2024 [5], showing the $5^{\text {th }}$ year of simulation. $U=0.15 \mathrm{~W} /\left(\mathrm{m}^{2} \mathrm{~K}\right)$.

\subsection{Risk of moisture-related damage}

Figure 3 illustrates the liquid moisture content in the interface between masonry and internal insulation as an indication for interstitial condensation risk.

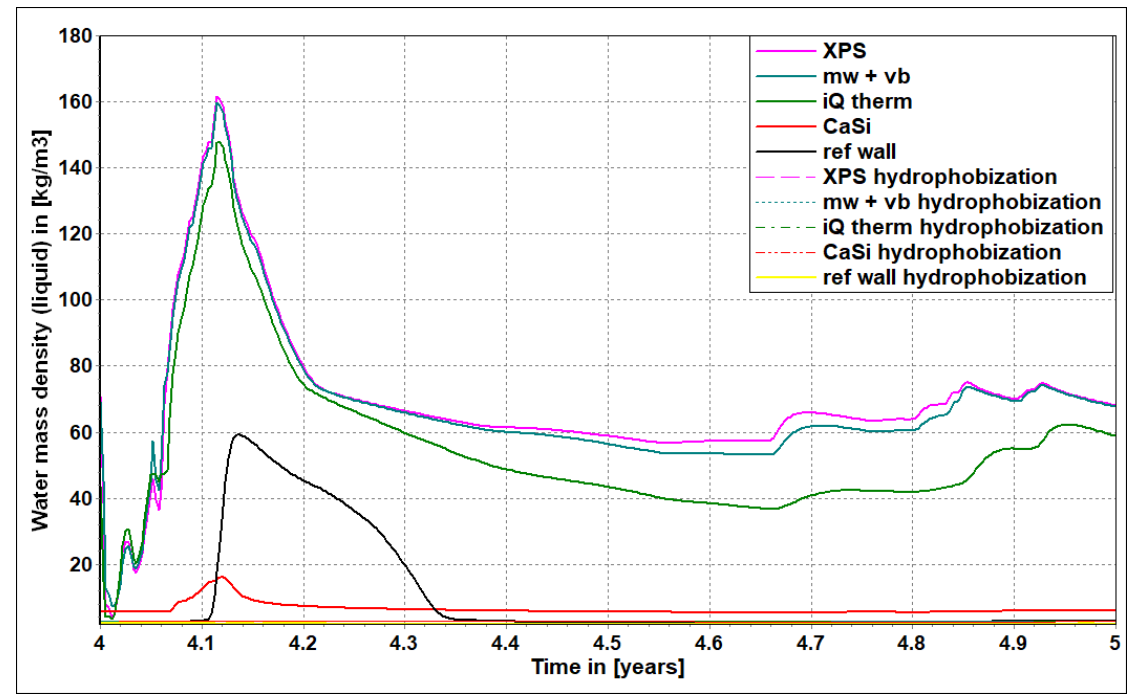

Fig. 3. Liquid moisture content in the interface between masonry and lime plaster before and after hydrophobization. Simulation based on climate data for Copenhagen 2020-2024 [5], showing the $5^{\text {th }}$ year of the simulation. SW orientation.

The moisture content during winter months in the reference wall dries out during the rest of the year, while this was not the case when adding XPS, mineral wool with vapor barrier or 
iQ-Therm insulation. CaSi has even lower moisture content than the reference wall. Hydrophobization eliminates the moisture content in the critical interface for any wall configuration.

According to the integrated VTT mould growth model in Delphin, there is a significant risk of mould growth formation (mould index 5) in the interior finishing in the SWoriented, uninsulated wall. However, by insulating the wall with any kind of internal insulation systems the risk for mould formation in the interior finishing is eliminated (see figure 4).

Both orientations (SW and NE) of uninsulated wall illustrate freeze thaw cycles with the SW-oriented having the highest number. Also, in both orientations the number of freeze thaw cycles is increased by adding any kind of internal insulation system, which indicates a potential frost damage risk.

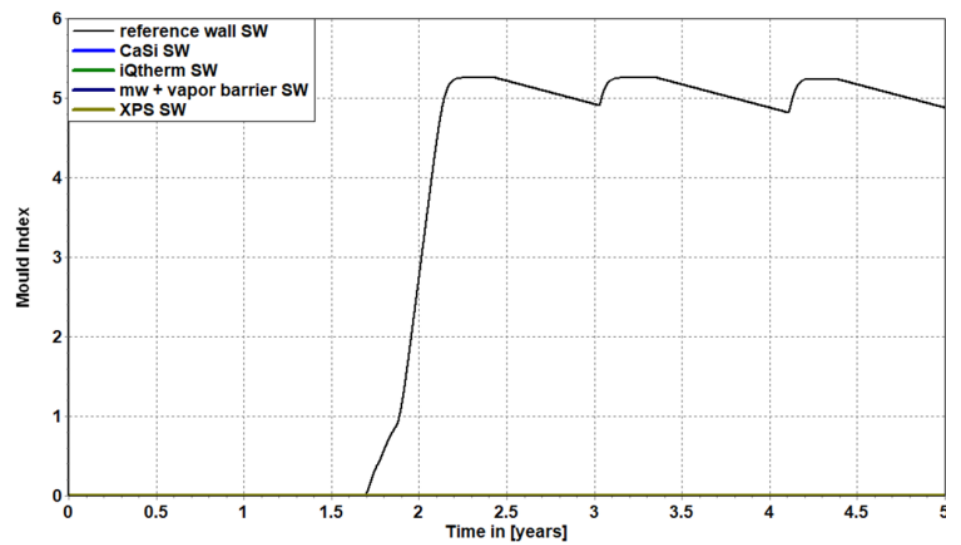

Fig. 4. Mould growth in the interior finishing. Simulation based on climate data for Copenhagen 2020-2024 [5]. SW orientation.

\subsection{Heat loss}

As expected, internal insulation significantly reduces the heat loss of the wall (Figure 5).

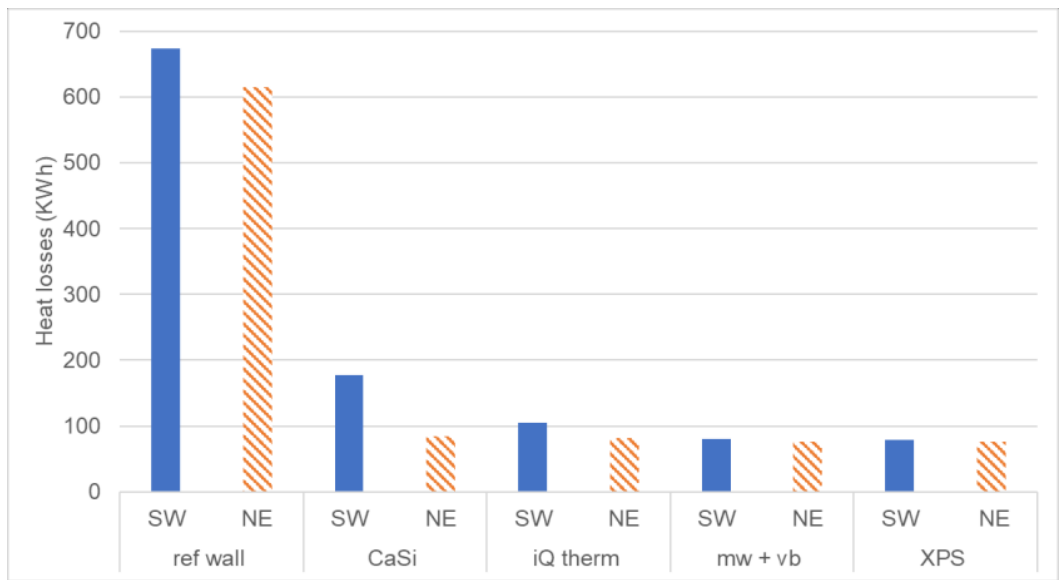

Fig. 5. Total heat loss, for five different insulated wall configurations, including reference wall. Simulation based on climate data for Copenhagen 2020-2024 [5]. 
The orientation of the façade influences the heat loss in the reference wall and in the case of applying CaSi and to a less extent iQ-Therm. An increased value of masonry thermal conductivity due to the higher moisture content in the SW façade could result in higher heat loss. Moreover, moisture transfer from masonry to more or less capillary active/open insulation systems (CaSi and iQ-Therm) could lead to higher thermal conductivity of the insulation that affects also negatively the heat loss. XPS and mineral wool with vapor barrier do not seem to be influenced by the wall orientation, as they are vapour tight and the masonry thermal conductivity increase could not affect the heat losses significantly.

\section{Conclusions and perspectives}

Simulations of SW oriented walls with U-value of $0.15 \mathrm{~W} /\left(\mathrm{m}^{2} \mathrm{~K}\right)$ in a historic building in Dianalund with climatic data covering estimated future weather for 2020-2024 shows an increased moisture content in the masonry when adding internal insulation and consequently higher risk for moisture-related damage, regardless of the insulation system (capillary active or vapour tight). The moisture content and risk for moisture-related damage is lower in insulated, NE oriented walls than in SW oriented, but still higher compared to an uninsulated wall. The addition of internal insulation, however, leads to a significant reduction of heat loss and reduces the risk of mould growth on the interior surface.

Hydrophobic impregnation of the internally insulated facades might be vital in avoiding moisture problems and securing a moisture-safe energy renovation of buildings like the one in Dianalund. However, to illustrate more accurate the behavior of the hydrophobic layer, determination of the hygric properties of hydrophobized materials instead of adjusting the boundary conditions (wind driven rain) is needed.

The present study is part of the project 'Moisture safe energy renovation of worth preserving external masonry walls', funded by the Danish foundations: The Landowners' Investment Foundation, The National Building Fund and Realdania. The material properties of the brick type used for simulations was measured by the Technical University of Denmark.

\section{References}

1. J. Grunewald, U. Ruisinger, P. Häupl, Proc. $3^{\text {rd }}$ Int. Conf. Building Physics: Research in Building Physics and Building Engineering, 27-31 Aug 2006, Montreal, Canada (P. Fazio, H. Ge, J. Rao, G. Desmarais (eds.)), CRC Press, 345-352 (2006)

2. E. Vereecken, S. Roels, Energy and Buildings, 80, 37-44 (2014)

3. Delphin software, TU Dresden, http://bauklimatik-dresden.de/delphin/index.php?aLa=en

4. Danish Building Regulations (BR18). www.bygningsreglementet.dk

5. Climate for Culture. www.climateforculture.eu

6. A. Hamid, P. Wallentén. Build. Environ., 123, 351-362 (2017) 